\title{
EFEKTIVITAS STRATEGI MENTAL CONTRASTING IMPLEMENTATION INTENTIONS (MCII) TERHADAP PENURUNAN KETERGANTUNGAN NIKOTIN PADA REMAJA AKHIR
}

\author{
Nurul Ismi ${ }^{1}$, Syarifah Faradina ${ }^{2}$ \\ 1,2Program Studi Psikologi, Fakultas Kedokteran, Universitas Syiah Kuala \\ e-mail: ${ }^{1}$ isminurul696@gmail.com, ${ }^{2}$ sy.faradina@ unsyiah.ac.id
}

\begin{abstract}
Abstrak. Perilaku merokok pada remaja akhir menjadi salah satu isu yang perlu mendapatkan perhatian khusus. Mental Constrating Implementation Intention (MCII) strategy merupakan salah satu strategi yang dapat diterapkan pada remaja perokok. Penelitian ini bertujuan untuk mengetahui efektivitas strategi MCII terhadap penurunan ketergantungan nikotin pada remaja akhir di Banda Aceh dengan melibatkan 13 sampel perokok dengan rentang usia 19-21 tahun dengan tingkat ketergantungan nikotin pada taraf rendah dan juga memiliki skor kejelasan citra visual yang tinggi. Metode penelitian yang digunakan adalah metode eksperimen dengan model pre-experimental design dengan bentuk one group pretest-posttest design. Alat ukur yang digunakan adalah Fagerstrom Test for Nicotine Dependence (FTND) dan Vividness of Visual Imagery Questionnaire-Revised Version (VVIQ-RV). FTND digunakan untuk mengukur tingkat ketergantungan nikotin, baik sebelum maupun sesudah diberi perlakuan, sedangkan kejelasan citra visual diukur (VVIQ-RV). Data dianalisis menggunakan metode nonparametrik yaitu Wilcoxon Signed-Rank Test formula dengan nilai signifikansi $(p)=0,001(p<0,05)$. Hasil ini menunjukkan bahwa terdapat perbedaan tingkat ketergantungan nikotin berdasarkan pengukuran FTND sebelum dan sesudah diberi perlakuan strategi MCII.
\end{abstract}

Kata Kunci: Mental Contrasting Implementation Intentions (MCII), Remaja, Rokok

Abstract. Smoking behavior in late adolescence is one issue that needs special attention. Mental Contrasting Implementation Intention (MCII) strategy is one of the strategies that can be applied to adolescent smokers. This study aims to determine the effectiveness of the MCII strategy for reducing nicotine dependence in late adolescents in Banda Aceh by involving 13 samples of smokers ranging in age from 19-21 years with low levels of nicotine dependence and also having high visual image clarity scores. The research method used is an experimental method with a pre-experimental design model in the form of one group pretest-posttest design. Measuring instruments used are the Fagerstrom Test for Nicotine Dependence (FTND) and Vividness of Visual Imagery Questionnaire-Revised Version (VVIQ-RV). FTND is used to measure the level of nicotine dependence, both before and after treatment, while visual image clarity is measured (VVIQ-RV). Data were analyzed using a nonparametric method namely the Wilcoxon SignedRank Test formula with a significance value $(p)=0.001(p<0.05)$. These results indicate that there are differences in the level of nicotine dependence based on FTND measurements before and after MCII strategy treatment.

Keywords: Adolescence, Cigarette, Mental Contrasting Implementation Intentions (MCII) 
Rokok menjadi salah satu penyebab terbesar kematian penduduk dunia. Menurut studi terbaru yang dipublikasikan di jurnal The Lancet pada tahun 2017, merokok menjadi salah satu penyebab dari sepuluh kematian yang terjadi di seluruh dunia (Britton, 2017). Hasil riset kesehatan dasar (Riskesdas) pada tahun 2013 menunjukkan bahwa rerata proporsi perokok di Indonesia adalah 29,3\% dan provinsi dengan proporsi perokok tertinggi adalah kepulauan Riau yaitu 27,2\%, disusul Aceh sebanyak 25\%. Global Youth Tobacco Survey (GYTS) menyatakan Indonesia sebagai negara dengan angka perokok remaja tertinggi di dunia (Kemenkes, 2015). Hasil survei tersebut juga didukung oleh penelitian yang dilakukan dari tahun 1990-2015 di 195 negara yang menunjukkan bahwa Indonesia menempati peringkat pertama prevalensi perokok laki-laki berusia 15-19 tahun yakni sebesar 27,7\%, disusul Rusia dan Jerman masing-masing 22,4\% dan 18,8\% (Gakidou, 2017).

Periode remaja merupakan salah satu tahap perkembangan yang penting dalam rentang kehidupan manusia. Menurut Hall (dalam Arnett, 1999), remaja adalah suatu periode kehidupan manusia yang sering disebut dengan istilah storm and stress dan dibebani oleh konflik dan gejolak emosi. Senang melakukan hal-hal yang berisiko merupakan salah satu ciri remaja. Bagi remaja, hal tersebut memberikan pengalaman baru dan pengalaman yang hebat, sehingga pada usia ini remaja sering terkait dengan perilaku-perilaku bermasalah, salah satunya yaitu perilaku merokok (Wulan, 2012). Masa remaja merupakan masa transisi menuju periode dewasa, sehingga remaja mulai mencoba untuk bergaya dan bertingkah laku seperti layaknya orang dewasa, salah satu tingkah laku yang diikuti adalah merokok (Wulan, 2012).

Perilaku merokok dikalangan remaja merupakan perilaku yang terus meluas dan juga merupakan isu utama yang telah diperbincangkan di seluruh dunia (Lamin, Othman, \& Othman, 2014). Sebuah penelitian yang dilakukan oleh US Department of Health \& Human Service pada tahun 1994 (dalam Lamin, Othman, \& Othman, 2014) mengindikasikan bahwa tingkat ketergantungan terhadap nikotin menjadi semakin tinggi pada individu yang telah mulai merokok sejak remaja dibandingkan individu yang mulai merokok pada usia dewasa. Hasil penelitian telah menunjukkan bahwa merokok pada masa remaja dan dewasa awal dapat menyebabkan kerusakan dini pada jantung dan paru-paru (CDC, 2012). Oleh karena banyaknya dampak negatif perilaku merokok bagi kesehatan, diperlukan intervensi yang dapat mengatasi permasalahan tersebut baik untuk mengurangi maupun menghentikan perilaku merokok pada remaja.

Banyak intervensi yang dapat dilakukan untuk mengatasi perilaku merokok, diantaranya yaitu pendekatan farmakoterapi (misalnya Bupropin, plester, permen karet, spray, dan inhaler) dan terapi alternatif lain seperti akupuntur, accupressure, dan hipnoterapi (Hasanah, 2014). Intervensi lain yang dapat dilakukan yaitu adanya intervensi yang komprehensif dari tingkat individu hingga tingkat pemerintah. Indonesia telah melaksanakan sebuah kebijakan untuk menanggulangi masalah rokok yaitu KTR (Kawasan Tanpa Rokok), namun belum seluruh daerah melaksanakannya secara optimal (Kemenkes, 2015). Prevalensi penerapan KTR di Provinsi Aceh hanya terlaksana sebanyak 21,74\%, jauh tertinggal dari Yogyakarta yang paling banyak menerapkan kebijakan tersebut yakni 80\% (Kemenkes, 2015). Lebih lanjut kebijakan 
tersebut dinilai belum terlalu kuat dalam penerapan sanksi dan implementasinya sehingga belum menunjukkan perubahan yang signifikan dalam mengatasi masalah rokok (Kemenkes, 2015).

Sebuah literatur menunjukkan bahwa untuk mengendalikan masalah merokok diperlukan intervensi yang dimulai dari tingkatan paling dasar, yaitu tingkat individu dengan menerapkan intervensi khusus untuk berhenti merokok (Browning \& Thomas, dalam Prawitasari, 2012). Salah satu intervensi singkat pada tingkat individu yang dapat digunakan untuk mengatasi masalah rokok yaitu strategi mental contrasting dan implementation intentions.

Strategi mental contrasting mengarahkan individu untuk membayangkan masa depan positif yang diinginkan bersamaan dengan realita negatif yang menjadi penghalang untuk tercapainya keinginan tersebut, sehingga dua hal tersebut dapat diakses secara bersamaan dan menciptakan hubungan yang kuat diantara keduanya (Duckworth, Grant, Loew, Oettingen, \& Gollwitzer, 2011). Implementation intentions merupakan strategi regulasi diri yang digunakan untuk melengkapi tujuan yang ingin dicapai oleh individu. Implementation intentions merupakan sebuah perencanaan yang secara detail menggambarkan kapan, dimana, dan bagaimana individu akan bertindak untuk merealisasikan keinginannya (Duckworth, Grant, Loew, Oettingen, \& Gollwitzer, 2011).

Mental contrasting dan implementation intentions merupakan strategi regulasi diri yang efektif ketika dilakukan secara terpisah, namun penelitian lainnya juga menyebutkan bahwa kombinasi dari kedua metode tersebut juga dapat menghasilkan pencapaian yang efektif dalam berbagai ruang lingkup penelitian. MCII (Mental Contrasting Implementation Intentions) merupakan kombinasi dua strategi regulasi diri (mental contrasting dan implementation intentions) untuk membentuk satu strategi kuat yang dapat digunakan dalam perubahan perilaku (Adriaanse, Oettingen, Gollwitzer, Hennes, Ridder, \& Wit, 2010).

Penelitian di bidang psikologi mengenai tujuan (goal) menunjukkan bahwa keberhasilan dalam pencapaian tujuan bergantung pada dua hal yaitu goal setting dan goal implementation. Perbedaan kedua hal tersebut pertama kalinya dijelaskan oleh Kurt Lewin (1926; Lewin, Dembo, Festinger, \& Sears, 1944 dalam Oettingen \& Gollwitzer, 2010). Para peneliti dalam bidang psikologi tertarik untuk mengetahui lebih lanjut mengenai bagaimana individu dapat mengatasi hambatan internal dan eksternal untuk mencapai tujuan yang diinginkan (Kirk, Oettingen, \& Gollwitzer, 2013).

Secara umum pencarian tujuan (goal pursuit) terdiri dari dua proses yang berbeda yaitu penetapan tujuan (goal setting), dan berjuang untuk mencapai tujuan tersebut (goal striving) (Oettingen \& Gollwitzer, dalam Kirk, Oettingen, \& Gollwitzer, 2013). Penelitian mengenai regulasi diri (self-regulation) yang mengidentifikasikan suatu strategi regulasi diri dalam menetapkaan tujuan (the self-regulation of goal setting) disebut dengan mental contrasting (Oettingen, dalam Kirk, Oettingen, \& Gollwitzer, 2013). Sedangkan penelitian mengenai goal striving lebih menunjukkan bahwa implementation intentions merupakan salah satu strategi yang dapat digunakan untuk menetapkan dan mencapai tujuan (Oettingen \& Gollwitzer, dalam Kirk, Oettingen, \& Gollwitzer, 2013). 
Strategi mental contrasting melibatkan fantasi mengenai masa depan yang diinginkan dan membandingkannya dengan hal negatif yang berhubungan dengan realita saat ini yang menjadi penghalang tercapainya masa depan yang diinginkan. Perbandingan secara mental antara masa depan dan realita saat ini mengarahkan individu untuk menentukan kemungkinan terwujudnya masa depan yang diinginkan ketika individu berkomitmen terhadap tujuannya. Jika kemungkinan tercapainya masa depan cukup tinggi, maka proses mental contrasting akan membentuk komitmen tujuan yang kuat, diikuti oleh usaha (goal striving) untuk mencapai tujuan tersebut (Kirk, Oettingen, \& Gollwitzer, 2013).

Penelitian mengenai goal striving menemukan bahwa penetapan tujuan dalam sebuah bentuk sederhana "jika-maka" (if-then plan) secara otomatis akan mengarahkan individu pada keinginan untuk mencapai tujuan. Oleh karena itu, implementation intentions digunakan sebagai strategi untuk mencapai sebuah tujuan yang diinginkan (Kirk, Oettingen, \& Gollwitzer, 2013). Strategi penetapan tujuan (goal-setting strategy), mental contrasting (MC) telah dikombinasikan dengan strategi pencarian tujuan (goal-striving strategy), implementation intentions (if-then plan) menjadi suatu strategi bersama yang disebut dengan Mental Contrasting Implementation Intention (MCII) dan digunakan sebagai intervensi yang diarahkan untuk meningkatkan pengaturan diri demi mencapai tujuan yang diinginkan (Kirk, Oettingen, \& Gollwitzer, 2013).

Gabriele Oettingen (1996) mengembangkan teori model of fantasy realization yang mengidentifikasikan mental contrasting sebagai salah satu strategi regulasi diri. Mental contrasting mengarahkan individu untuk membayangkan suatu fantasi yang ingin dicapai (misalnya melakukan presentasi yang baik pada saat konferensi), kemudian merefleksikan kenyataan yang menjadi penghalang untuk mencapai tujuan yang diinginkan (misalnya merasa cemas) (Oettingen, 2012).

Gollwitzer (1993, 1999) memperkenalkan konsep implementation intentions berdasarkan penelitian mengenai perencanaan untuk meningkatkan pencapaian tujuan (Gollwitzer, 2014). Implementation intentions adalah rencana tindakan sederhana dengan format jika-maka (if-then) yang menentukan kapan, di mana dan bagaimana keinginan atau niat dari sebuah tujuan dapat direalisasikan dalam bentuk perilaku atau tindakan (Gollwitzer, 2014).

MCII merupakan kombinasi dua strategi regulasi diri yang sudah banyak digunakan dalam berbagai penelitian (mental contrasting dan implementation intentions) untuk membentuk satu strategi ampuh dalam mengubah suatu perilaku (Stadler, Oettingen, \& Gollwitzer, 2009). Strategi MCII mengarahkan individu mengikuti latihan mental contrasting terlebih dahulu untuk menciptakan komitmen tujuan yang kuat dan untuk mengidentifikasi hambatan yang menghalangi pencapaian tujuan. Implementation intentions (if-then plan) kemudian dibentuk untuk membantu menerjemahkan komitmen tujuan ke dalam perilaku yang sebenarnya (Houssais, Oettingen, \& Mayer, 2013). Mental Contrasting Implementation Intentions (MCII) terdiri atas 4 tahapan yang berurutan yaitu: Wish, Outcome, Obstacle, dan Plan (SaddawiKonefka, Baker, Guarino, Burns, Oettingen, Gollwitzer, \& Charnin, 2017). 
Mental Contrasting Implementation Intentions (MCII) terdiri atas 4 tahapan yang berurutan (Saddawi-Konefka, Baker, Guarino, Burns, Oettingen, Gollwitzer, \& Charnin, 2017), yaitu:

a) Wish

Wish (harapan) adalah tahap pertama yang berfungsi untuk mengidentifikasi tujuan yang bermakna.

b) Outcome

Outcome merupakan tahap kedua yang bertujuan untuk mengidentifikasi dan membayangkan hasil terbaik dari pencapaian tujuan.

c) Obstacle

Obstacle merupakan tahap ketiga yang bertujuan untuk mengidentifikasi dan membayangkan hambatan yang ada untuk pencapaian tujuan.

d) Plan

Plan merupakan tahap terakhir yang mengarahkan individu agar membentuk rencana "if-then" untuk mengatasi hambatan dalam bentuk, "jika (hambatan), maka saya akan (bertindak untuk mengatasi hambatan).

Leventhal dan Clearly (1980) menggambarkan perilaku merokok sebagai perilaku kompleks yang berkembang melalui beberapa tahap, yaitu: tahap preparation, initiation, becoming $a$ smoker, dan maintenance of smoking.

Leventhal dan Clearly (1980) menjelaskan bahwa terdapat empat aspek perilaku merokok, yaitu:

a) Fungsi Merokok

Fungsi merokok ditunjukkan dengan perasaan yang dialami perokok. Seseorang menjadikan merokok sebagai penghibur dan memiliki fungsi yang penting bagi kehidupannya.

b) Intensitas Merokok

Seseorang yang merokok dengan jumlah batang rokok yang banyak dalam waktu satu hari menunjukkan perilaku merokoknya sangat tinggi.

c) Tempat Merokok Individu yang merokok di mana saja, bahkan merokok di area no smoking menunjukkan perilaku merokok individu tersebut sangat tinggi.

d) Waktu Merokok

Perilaku merokok individu dikatakan sangat tinggi ketika mereka merokok di segala waktu (pagi, siang, sore, dan malam) dan dipengaruhi oleh keadaan yang dialami pada saat itu. Misalnya ketika sedang berkumpul dengan teman, cuaca dingin, atau setelah dimarahi oleh orangtua. 


\section{METODE}

Penelitian ini menggunakan desain penelitian eksperimen dengan model Pre-Experimental Design dengan teknik One-Group Pretest-Posttest Design.

Tabel 1.

Desain Penelitian One-Group Pretest-Posttest Design

\begin{tabular}{ccc}
\hline Pretest & Treatment & Posttest \\
\hline $\mathrm{O} 1$ & $\mathrm{X}$ & O2 \\
\hline
\end{tabular}

Keterangan:

O1 = Pengukuran awal kelompok eksperimen

$\mathrm{O} 2=$ Pengukuran akhir kelompok eksperimen

$\mathrm{X} \quad=$ Treatment (Perlakuan)

Sampel dalam penelitian ini dipilih dengan menggunakan metode non-probability sampling dengan teknik purposive sampling yakni penentuan sampel dilakukan karena ada pertimbangan tertentu yang menjadi tujuan penelitian (Idrus, 2009). Kriteria sampel penelitian adalah memiliki keinginan untuk berhenti merokok, berada di rentang usia remaja akhir yaitu 19-21 tahun, merupakan perokok dan berada pada rentang low berdasarkan hasil tes skala FTND (Fagerstrom Test for Nicotine Dependence), dan memiliki perolehan skor high berdasarkan tes VVIQ-RV. Setelah proses screening diperoleh 13 sampel yang bersedia menjadi subjek penelitian dan diberi perlakuan MCII.

Tahapan pertama dalam pelaksanaan penelitian yaitu mempersiapkan alat ukur untuk pengumpulan data penelitian yaitu FTND dan VVIQ-RV, melakukan alih bahasa kedua skala pengukuran menjadi bahasa Indonesia, melakukan uji coba (try out). Sampel yang memenuhi kriteria dihubungi oleh peneliti untuk mengikuti proses eksperimen. Skor FTND sampel pada saat screening akan menjadi nilai pretest sehingga bagi sampel yang memenuhi kriteria dan bersedia, tidak lagi diberi pretest sebelum adanya perlakuan. Perlakuan MCII terdiri atas 4 form yaitu Wish, Outcome, Obstacle, dan Plan (WOOP). Satu minggu sebelum diberi posttest, subjek dibekali dengan smoking diary yang harus diisi setiap harinya. Smoking diary ini terdiri dari beberapa pertanyaan mengenai aktivitas merokok harian, refleksi aktivitas setiap harinya dan jumlah rokok yang dihisap perhari beserta dengan waktunya. Pelaksanaan penelitian dan pembagian tugas eksperimen secara lebih rinci dapat dilihat pada tabel berikut. 
Tabel 2.

Pelaksanaan Penelitian

\begin{tabular}{c|l}
\hline Waktu & \multicolumn{1}{c}{ Kegiatan } \\
\hline 5 menit & Peneliti menjelaskan instruksi Wish kepada peserta \\
\hline 15 menit & Peserta melakukan kegiatan Wish \\
\hline 5 menit & Peneliti menjelaskan instruksi Outcome kepada peserta \\
\hline 15 menit & Peserta melakukan kegiatan Outcome \\
\hline 5 menit & Peneliti menjelaskan instruksi Obstacle kepada peserta \\
\hline 15 menit & Peserta melakukan kegiatan Obstacle \\
\hline 5 menit & Peneliti menjelaskan instruksi Plan kepada peserta \\
\hline 15 menit & Peserta melakukan kegiatan Plan \\
\hline 10 menit & Peneliti menjelaskan mengenai smoking diary untuk diisi selama 7 hari \\
\hline
\end{tabular}

Tabel 3.

Pembagian tugas eksperimen Mental Contrasting Implementation Intentions

\begin{tabular}{ll}
\hline Materi & Tugas \\
\hline Wish & $\begin{array}{l}\text { Diberikan 1 lembar kertas yang dilengkapi instruksi untuk menuliskan } \\
\text { keinginan yang dapat mereka penuhi dengan mengubah kebiasaan } \\
\text { merokok }\end{array}$
\end{tabular}

Outcome Diberikan 1 lembar kertas yang dilengkapi instruksi untuk menuliskan 1 aspek positif yang akan terjadi jika mereka dapat memenuhi keinginannya untuk berhenti merokok. Kemudian menguraikan aspek tersebut pada lembar yang telah disediakan berdasarkan instruksi yang ada.

Obstacle Diberikan 1 lembar kertas yang dilengkapi instruksi untuk menuliskan hambatan yang menjadi penghalang dalam keinginan untuk menghilangkan kebiasaan merokok. Kemudian uraikan aspek tersebut pada lembar yang telah disediakan berdasarkan instruksi yang ada.

Plan Diberikan 1 lembar kertas yang dilengkapi format if then plan. Jika saya (hambatan) maka saya akan (rencana). Partisipan mengisi rencana yang akan dilakukan berdasarkan hambatan yang telah diidentifikasi sebelumnya. 
Data yang didapatkan dianalisis menggunakan metode uji asumsi yang terdiri dari uji normalitas dan uji homogenitas. Setelah uji asumsi terpenuhi kemudian dilakukan uji hipotesis secara nonparametrik.

Penelitian ini dilakukan pada remaja akhir berusia 19-21 tahun yang merokok. Jumlah sampel penelitian setelah proses screening didapatkan sebanyak 13 individu yang memenuhi kriteria sampel penelitian yaitu memiliki tingkat ketergantungan nikotin low dengan kisaran skor 3-4 berdasarkan FTND dan memiliki nilai kejelasan citra visual yang high dengan rata-rata skor (mean) subjek sebesar 121 berdasarkan VVIQ-RV. Data demografi sampel penelitian yang diperoleh dari hasil penelitian dapat dilihat pada tabel di bawah ini:

Tabel 4.

Data demografi berdasarkan karakteristik responden penelitian

\begin{tabular}{ccccc}
\hline No & Karakteristik & Kategori & F & \% \\
\hline 1 & Usia & 19 Tahun & 1 & $7,69 \%$ \\
& & 21 Tahun & 12 & $92,31 \%$ \\
2 & Jenis Kelamin & Laki-laki & 13 & $100 \%$ \\
3 & Status pekerjaan & Bekerja & 1 & $7,69 \%$ \\
& & Mahasiswa & 12 & $92,31 \%$ \\
4 & Skor FTND (Low) & 3 & 9 & $69,23 \%$ \\
& & 4 & 4 & $30,77 \%$ \\
\hline
\end{tabular}

Berdasarkan tabel karakteristik responden penelitian di atas, dapat dilihat bahwa sampel penelitian seluruhnya memiliki tingkat ketergantungan nikotin low berdasarkan skala FTND yaitu sejumlah 13 sampel (100\%), hal ini sesuai dengan karakteristik penelitian yang dipaparkan sebelumnya. Selain itu sampel penelitian seluruhnya berjenis kelamin laki-laki (100\%) dan didominasi oleh kelompok usia 21 tahun sejumlah 12 sampel (92,31\%). Kemudian berdasarkan status pekerjaan, sampel juga didominasi oleh mahasiswa sejumlah 12 sampel $(92,31 \%)$.

\section{HASIL}

Hasil penelitian menunjukkan sampel mengalami penurunan tingkat ketergantungan nikotin dari low menjadi very low. Uji normalitas dengan teknik statistik One Sample Kolmogorov Smirnov menunjukkan nilai signifikansi pada pretest 0,016 dan posttest 0,037 , keduanya menunjukkan $\mathrm{p}<0,05$ sehingga data penelitian tidak berdistribusi normal. Hasil uji homogenitas menunjukkan nilai signifikansi 0,443 yang artinya $p>0,05$ sehingga data penelitian ini mempunyai varian yang sama atau dengan kata lain varian datanya bersifat homogen.

Hasil uji asumsi menunjukkan data tidak berdistribusi normal namun homogen, maka langkah selanjutnya adalah melakukan uji hipotesis dengan teknik nonparametrik yaitu uji Wilcoxon 
Signed-Rank Test. Adapun hasil perhitungan analisis dengan uji Wilcoxon dapat dilihat pada tabel di bawah ini:

Tabel 5.

Analisis wilcoxon pretest dan posttest sampel

\begin{tabular}{ccclcc}
\hline FTND & N & Mean Rank & Sum of Ranks & Z & Sig. \\
\hline Posttest-Pretest & 13 & 7,00 & 91,00 & $-3,228$ & \\
& 0 & 00 & 0,00 & & 0,001 \\
0 & 13 & & & & \\
\hline
\end{tabular}

Hasil analisis menunjukkan 13 data pada kolom negative ranks atau selisih negatif antara pretest dan posttest. Hal ini mengindikasikan bahwa ke 13 sampel mengalami penurunan tingkat ketergantungan nikotin dari nilai pretest ke nilai posttest. Hasil output "Test Statistics" menunjukkan nilai signifikansi $0,001(\mathrm{p}<0,05)$ yang menunjukkan hipotesis diterima sehingga dapat disimpulkan terdapat perbedaan tingkat ketergantungan nikotin pada remaja akhir sebelum dan sesudah diberi perlakuan mental contrasting implementation intentions.

Tabel 5.

Skor FTND

\begin{tabular}{ccc}
\hline No. Subyek & \multicolumn{2}{c}{ Skor FTND } \\
\cline { 2 - 3 } & Pre-Test & Post-Test (1 minggu kemudian) \\
\hline 1. & 3 & 2 \\
\hline 2. & 3 & 2 \\
\hline 3. & 4 & 1 \\
\hline 4. & 3 & 1 \\
\hline 5. & 3 & 1 \\
\hline 6. & 3 & 2 \\
\hline 7. & 4 & 2 \\
\hline 8. & 4 & 1 \\
\hline 9. & 4 & 1 \\
\hline 10. & 3 & 1 \\
\hline 11. & 3 & 1 \\
\hline 12. & 3 & 2 \\
\hline 13. & 3 & 1 \\
\hline Rata-rata & 3,31 & 1,38 \\
\hline
\end{tabular}

Hasil penelitian menunjukkan bahwa individu yang telah mengikuti perlakuan menunjukkan penurunan skor tingkat ketergantungan nikotin berdasarkan skala FTND. Hal ini dibuktikan dengan nilai rata-rata yang diperoleh sebelum diberi perlakuan sebesar 3,31 dan seminggu kemudian sesudah diberi perlakuan sebesar 1,38. Selain itu, hasil kategorisasi sampel sebelum 
perlakuan berada pada rentang low, sesudah diberi perlakuan berada pada rentang very low. Hal ini memperkuat hasil penelitian bahwa terdapat perubahan tingkat ketergantungan nikotin pada sampel, seminggu sesudah diberikan perlakuan MCII.

\section{DISKUSI}

Penelitian ini bertujuan untuk mengetahui efektivitas strategi Mental Contrasting Implementation Intentions (MCII) terhadap konsumsi rokok pada remaja akhir di Banda Aceh. Sampel yang telah memenuhi kriteria dan bersedia menjadi responden selanjutnya diberi perlakuan untuk mengisi form WOOP (Wish, Outcome, Obstacle, Plan) berkaitan dengan perilaku merokok. Hasil pengisian form wish menunjukkan bahwa sampel mendeskripsikan keinginan untuk berhenti dan mengurangi perilaku merokok, namun sebagian besar sampel menuliskan bahwa untuk berhenti dari suatu kebiasaan membutuhkan waktu yang lama dan dengan proses yang panjang. Sehingga sampel penelitian menuliskan harapan agar berhasil mengurangi jumlah batang rokok perharinya dalam 7 hari kedepan.

Hasil pengisian form outcome menunjukkan hampir seluruh sampel menuliskan bahwa rokok membawa dampak buruk bagi kesehatan dan sebagian sampel juga menuliskan bahwa rokok telah menghabiskan banyak pengeluaran untuk sesuatu yang tidak berdampak positif. Sampel menguraikan secara rinci hal positif yang akan terjadi apabila mampu berhenti merokok seperti dapat menjaga kesehatan, melakukan penghematan, memiliki kebiasaan olahraga dan dapat bangun lebih pagi.

Seluruh sampel menuliskan bahwa pengaruh yang paling besar dan menjadi hambatan (obstacle) terhadap kebiasaan merokok adalah lingkungan yang terdiri dari teman dekat dan orang-orang yang ada di lingkungan sekitar. Kebiasaan berkumpul bersama teman menjadi salah satu hal yang membuat rokok tidak bisa ditinggalkan dalam kehidupan sehari-hari. Kemudian sebagian sampel juga menuliskan bahwa kebiasaan merokok setelah makan sangat sulit untuk ditinggalkan karena sudah menjadi suatu hal yang terus menerus dilakukan. Selain itu, salah satu sampel menuliskan bahwa rendahnya keinginan dalam diri untuk berhenti merokok juga memengaruhi keberhasilan untuk berhenti merokok.

Sampel menuliskan perencanaan (plan) yang akan dilakukan ketika dihadapkan pada suatu kondisi yang menjadi hambatan dalam mewujudkan keinginan mengurangi kebiasaan merokok. Tujuh sampel menuliskan hambatan yang akan mereka temui ketika mencoba berhenti adalah pengaruh teman, lalu sampel membuat perencanaan untuk menghindari atau mengatasi keberadaan teman dan lingkungan sekitar agar tidak mengganggu proses mengurangi kebiasaan merokok. Kemudian 6 sampel lain mengidentifikasi hambatannya dengan kebiasaan setelah makan, terpapar dengan perokok yang ada di lingkungan sekitar, dan merasa depresi, kemudian merencanakan aktivitas peralihan yang lebih positif, menggantikannya dengan aktivitas makan, tidur, melakukan hal-hal yang digemari, menggantikan kebiasan setelah makan dengan membeli permen, dan berusaha untuk terus mengurangi kebiasaan merokok. 
Setelah sampel mengikuti perlakuan WOOP, sampel dibekali dengan jurnal harian (smoking diary) yang diisi selama satu minggu. Hasil pengisian smoking diary sampel menunjukkan bahwa dalam aktivitas sehari-hari dimulai dari bangun tidur hingga beraktivitas, jumlah konsumsi rokok cukup variatif berkisar antara 1-25 batang setiap harinya. Satu minggu kemudian, sampel diberikan posttest berupa skala FTND untuk mengukur kembali tingkat ketergantungan nikotin. Hasil pengukuran menunjukkan tingkat ketergantungan nikotin pada sampel telah menurun dari kisaran skor 3-4 (low) menjadi 1-2 (very low).

Ockene (dalam Oettingen, Mayer, \& Thorpe, 2010) menyebutkan bahwa individu yang ingin berhasil menjalankan penanganan untuk berhenti merokok harus memiliki niat atau kemauan untuk mengurangi konsumsi rokok. Hal ini membuktikan bahwa individu perlu memiliki komitmen agar tujuan untuk berhenti atau mengurangi konsumsi rokok dapat terealisasikan (Oettingen, Mayer, \& Thorpe, 2010). Mental contrasting implementation intentions sebagai salah satu strategi regulasi diri membantu individu untuk berkomitmen dalam mewujudkan tujuan yang diinginkan. Komitmen sampel untuk berhenti merokok terlihat pada pengisian form wish. Keseluruhan sampel menuliskan harapan dan keinginan untuk mengurangi jumlah konsumsi rokok dalam waktu satu minggu ke depan.

Metode mental contrasting menimbulkan perubahan yang tersirat pada kognisi dan juga menstimulasi energi yang dapat memprediksikan pencapaian tujuan yang selektif dan perubahan perilaku (Oettingen, 2012). Penelitian secara neurologis menunjukkan bahwa secara kognitif mental contrasting menuntut latihan mental yang dapat menyelesaikan suatu permasalahan (Oettingen, 2012).

Menerapkan metode mental contrasting artinya terjadi proses yang membuat keinginan individu di masa mendatang dapat dicapai dengan mengatasi hambatan (Oettingen, 2012). Besarnya ekspektasi akan kesuksesan memberikan pengaruh pada keberhasilan, hanya jika individu memiliki ekspektasi akan keberhasilan yang tinggi maka keinginan tersebut dapat dicapai, sehingga sejauh mana harapan seseorang akan keberhasilan sangat dipengaruhi (Oettingen, 2012).

Hasil penelitian lainnya juga menjelaskan salah satu proses motivasional yang memengaruhi keberhasilan strategi mental contrasting dikarenakan munculnya perasaan yang menimbulkan energi (Oettingen, 2012). Para pelopor penelitian mengenai goal setting mengidentifikasi bahwa salah satu hal penting yang mendukung perilaku yang terbentuk berdasarkan tujuan adalah seberapa besar energi yang dimiliki seseorang (Locke \& Latham dalam Oettingen, 2012). Hasil penelitian yang dilakukan oleh Oettingen (2009) juga menunjukkan bahwa perasaan berenergi menjelaskan secara signifikan bahwa harapan akan kesuksesan akan sangat memengaruhi komitmen seseorang untuk mencapai tujuan yang diinginkan.

Proses kognisi dari mental contrasting juga dijelaskan melalui hasil magnetoencephalography (MEG) yang menunjukkan bahwa mental contrasting merupakan suatu strategi yang mengaktivasi area otak melibatkan working memory, episodic memory, intention maintenance, action preparation, dan vivid visualisation. Mental contrasting juga menstimulasi wawasan baru, 
kreativitas, dan kemampuan negosiasi integratif dalam mencapai kesuksesan salah satunya mengatasi permasalahan berkaitan dengan kebiasaan yang tidak baik (bad habits) (Oettingen, 2012).

Bagian terakhir dari perlakuan yakni Plan merupakan bentuk dari implementation intentions. Membentuk implementation intentions yang berhubungan dengan suatu kebiasaan dapat membantu individu untuk merealisasikan tujuan dalam memodifikasi kebiasaan yang tidak diinginkan. Perencanaan if-then mempromosikan secara relatif situasi-respon yang otomatis menimbulkan pembentukan tujuan yang ingin dicapai (Webb \& Sheeran dalam Webb, Sheeran, \& Luszczynska, 2009).

Salah satu hal yang memengaruhi efektivitas strategi MCII merupakan tingkat ketergantungan nikotin sampel. Berdasarkan penelitian yang dilakukan oleh Webb, Sheeran, dan Luszczynska (2009) kekuatan dari kebiasaan (habit strength) dapat memoderasi dampak implementation intentions terhadap pencapaian tujuan. Hasil penelitian menunjukkan bahwa strategi implementation intentions hanya efektif menurunkan kebiasaan merokok pada sampel yang tingkat ketergantungannya masih berada di tahap rendah atau sedang (Webb, Sheeran, \& Luszczynska, 2009).

\section{SIMPULAN DAN IMPLIKASI}

Hasil penelitian menunjukkan bahwa individu yang telah mengisi formulir wish, outcome, obstacle, dan plan menunjukkan penurunan skor tingkat ketergantungan nikotin berdasarkan skala FTND dari pretest ke posttest. Berdasarkan hasil tersebut dapat disimpulkan MCII dapat menjadi strategi yang efektif untuk mengatasi kebiasaan merokok pada remaja akhir di Banda Aceh.

Hasil penelitian ini menunjukkan bahwa terdapat perbedaan tingkat ketergantungan nikotin sebelum dan sesudah diberi perlakuan pada remaja akhir yang merokok di Banda Aceh. Perlakuan Mental Contrasting Implementation Intentions (MCII) dengan formulir wish, outcome, obstacle, dan plan mengarahkan sampel untuk menurunkan jumlah konsumsi rokok dalam waktu satu minggu. strategi Mental Contrasting Implementation Intentions (MCII) memengaruhi kognisi sampel dengan membentuk keinginan mengurangi konsumsi rokok sehingga menstimulasi perilaku dengan membuat perencanaan disertai tindakan yang akan dilakukan untuk mengatasi hambatan yang akan menghalangi proses pengurangan konsumsi rokok. Hasil pengukuran menunjukkan sampel sebelum diberi perlakuan memiliki tingkat ketergantungan nikotin low dan setelah diberi perlakuan turun menjadi very low.

Peneliti selanjutnya diharapkan dapat melakukan penelitian lanjutan mengenai strategi Mental Contrasting Implementation Intentions (MCII) dengan perlakuan lebih dari satu kali dan kontrol yang lebih ketat sehingga memberikan hasil yang lebih kaya dan akurat. Selain itu diharapkan 
dapat menjaring sampel yang lebih banyak sehingga menghasilkan sebuah kesimpulan yang dapat digeneralisasikan dan lebih luas.

\section{REFERENSI}

Adriaanse, M. A., Oettingen, G., Gollwitzer, P. M., Hennes, E. P., Ridder, D. T. D., \& Wit, J. B. F. D. (2010). When planning is not enough: Fighting unhealthy snacking habits by mental contrasting with implementation intention (MCII). European Journal of Social Psychology, 40, 1277-1293. doi: 10.1002/ejsp.730

Arnett, J. J. (1999). Adolescent storm and stress, reconsidered. American Psychological Association, 54 (5), 317-326.

Britton, J. (2017). Death, disease, and tobacco. The Lancet Journal, 389(10082), 1861-1862. doi: http://dx.doi.org/10.1016/S0140-6736(17)30867-X

Centers for Disease Control and Prevention. (2012). Preventing Tobacco Use Among Youth and Young Adults. A Report of the Surgeon General. Diakses pada tanggal 11 Desember 2017 dari https://www.surgeongeneral.gov/library/reports/preventing-youth-tobacco$\underline{\text { use/index.html }}$

Duckworth, A. L., Grant, H., Loew, B., Oettingen, G., \& Gollwitzer, P. M. (2011). Selfregulation strategies improves self-discipline in adolescents: benefits of mental contrasting and implementation intentions. Educational Psychology, 31, (1), 17-26. doi: $10.1080 / 01443410.2010 .506003$

Gakidou, E. (2017). Smoking prevalence and attributable disease burden in 195 countries and territories, 1990-2015: A systematic analysis from the Global Burden of Disease Study 2015. Journal The Lancet, 389, 1885-1906.

Gollwitzer, P. M. (1999). Implementation intentions: Strong effects of simple plans. American Psychologist, 54, 493-503.

Gollwitzer, P. M. (2014). Weakness of the will: Is a quick fix possible? Motivation and Emotion, $38,305-322$.

Hasanah, H. (2014). Baby Smoker: Perilaku konsumsi rokok pada anak dan strategi dakwahnya. Jurnal Sawwa, 9(12), 253-274. 
Houssais, S., Oettingen, G., \& Mayer, D. (2013). Using mental contrasting with implementation intentions to self regulate insecurity-based behaviors in relationships. Motivation and Emotion, 37, 224-233. doi: 10.1007/s11031-012-9307-4

Kementerian Kesehatan Republik Indonesia. (2015). Perilaku merokok masyarakat Indonesia. Diakses pada 29 September 2017 dari http://www.depkes.go.id/folder/view/01/structurepublikasi-pusdatin-info-datin.html

Kirk, D., Oettingen, G., \& Gollwitzer, P. M. (2013). Promoting integrative bargaining: mental contrasting with implementation intentions. International Journal of Conflict Management, 24 (2), 148-165.

Lamin, R. A. C., Othman, N., \& Othman, C. N. (2014). Effect of smoking behavior on nicotine dependence level among adolescents. Procedia-Social and Behavioral Sciences, 153, 189198. doi: $10.1016 /$ j.sbspro.2014.10.053

Oettingen, G., Mayer, D., \& Thorpe, J. (2010). Self-regulation of commitment to reduce cigarette consumption: Mental contrasting of future with reality. Psychology and Health, 25(8): 961977. doi 10.1080/08870440903079448

Oettingen, G. (2012). Future thought and behaviour change. European Review of Social Psychology, 23, 1-63.

Prawitasari, J. E. (2012). Psikologi Terapan Melintas Batas Disiplin Ilmu. Jakarta: Penerbit Erlangga.

Saddawi-Konefka, D., Baker, K., Guarino, A., Burn, S. M., Oettingen, G., Gollwitzer, M. P., \& Charnin, J. E. (2017). Changing resident physician studying behaviors: A randomized, comparative effectiveness trial of goal setting versus use of WOOP. Journal of Graduate Medical Education, 451-457. doi: http://dx.doi.org/10/4300/JGME-D-16-00703.1

Stadler, G., Oettingen, G., \& Gollwitzer, P. M. (2009). Physical activity in women effects of a self-regulation intervention. American Journal of Preventive Medicine, 36(1), 29-34. doi: 10.1016/j.amepre.2008.09.021

Webb, T. L., Sheeran, P., \& Luszcynska, A. (2009). Planning to break unwanted habits: Habit strength moderates implementation intention effects on behaviour change. Brtish Journal of Social Psychology, 48, 507-523. doi: 10.1348/014466608X37059

Wulan, D. K. (2012). Faktor psikologis yang mempengaruhi perilaku merokok pada remaja. Jurnal Humaniora, 3(2), 504-511. 